\title{
DESIGN E ACESSIBILIDADE: pessoas com deficiência em centros históricos
}

\section{DESIGN AND ACCESSIBILITY: people with disabilities in historic centers}

\author{
COSTA, Andréa Katiane Ferreira \\ Universidade Federal do Maranhão - UFMA, Doutoranda \\ andrea.katianefc@gmail.com \\ LANDIM, Paula da Cruz \\ Universidade Estadual Paulista - UNESP, Doutora \\ paula.cruz-landim@unesp.br \\ PASCHOARELLI, Luis Carlos \\ Universidade Estadual Paulista - UNESP, Doutor \\ luis.paschoarelli@unesp.br
}

\section{RESUMO}

Este artigo traz a discussão sobre as intervenções para viabilizar acessibilidade das pessoas com deficiência e mobilidade reduzida aos centros históricos, considerando a dicotomia de dois tema amparados por lei. Com o objetivo de refletir sobre a acessibilidade no Centro Histórico de São Luís, o presente artigo apresenta problemas e soluções encontradas nas dimensões internacionais e nacionais. Para isso apresenta revisão da literatura, o estado da arte. O trabalho encontra-se em fase inicial, pretende partir para o teste piloto utilizando métodos e técnicas de design participativo, além da adaptação de outras ferramentas como a experiência do usuário. Considerando a NBR 9050 - que aborda a acessibilidade física - e atende os preceitos do Desenho Universal. A partir de experiências desenvolvidas em centros históricos de outras cidades no Brasil e no mundo, percebe-se que tanto os problemas quanto as soluções podem ser muito parecidas em determinadas cidades e muito diferentes para alguns centros históricos com vistas a alcançar a acessibilidade para todos. Alguns fatores relacionados a educação e cultura, ou seja, fatores comportamentais, atitudinais, podem influenciar na tomada de decisão quanto as soluções mais adequadas para cada caso. 


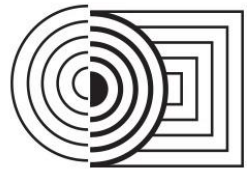

\section{$17^{\circ}$ ERGODESIGN \& USIHC 2019 \\ PUC-Rio, 11 a 13 de dezembro \\ Rio de Janeiro, RJ, Brasil}

$17^{\circ}$ Ergodesign - Congresso Internacional de Ergonomia e Usabilidade de Interfaces Humano Tecnológica: Produto, Informações Ambientes Construídos e Transporte

$17^{\circ}$ USIHC - Congresso Internacional de Ergonomia e Usabilidade de Interfaces Humano Computador

\begin{abstract}
This article discusses the interventions to enable accessibility for people with disabilities and reduced mobility to historic centers, considering the dichotomy of two themes supported by law. In order to reflect on accessibility in the Historic Center of São Luís, this article presents problems and solutions found in the international and national dimensions. For this presents literature review, the state of the art. The work is in its initial phase, it intends to go to the pilot test using participatory design methods and techniques, besides adapting other tools such as the user experience. Considering NBR 9050 - which addresses physical accessibility - and meets the precepts of Universal Design. From experiences developed in historical centers of other cities in Brazil and around the world, it is clear that both problems and solutions can be very similar in certain cities and very different for some historical centers in order to achieve accessibility for all. Some factors related to education and culture, that is, behavioral and attitudinal factors, can influence the decision making regarding the most appropriate solutions for each case.
\end{abstract}

accessibility, historical centers, people with disabilities, design, Technologies

\title{
1. INTRODUÇÃO
}

A preservação do patrimônio cultural edificado e acessibilidade são temas complexos, amparados por lei e conflitantes. Entretanto, considerando o desenho universal, existem exemplos de cidades que atingiram níveis satisfatórios de acessibilidade.

O Centro Histórico de São Luís conta com a proteção municipal, estadual (conforme Decreto $\mathrm{n}^{0}$ 10.089/1986) e federal de tombamento (processo 509-T/1974), totalizando 5.500 imóveis. Desde 1997 é reconhecida como Patrimônio da Humanidade, pela UNESCO - United Nation Educational, Scientific and Cultural Organization. A partir de 2011 a área federal de tombamento passa a coincidir com a área reconhecida como Patrimônio Mundial, com cerca de 1.200 imóveis. A despeito desse título o sítio histórico de São Luís é palco de diversas contradições entre elas a insegurança, o abandono e a falta de acessibilidade.

A fim de propor reflexões a partir de um olhar para experiências já desenvolvidas, este artigo traz exemplos de cidades que assim como a capital do Maranhão, são patrimônio histórico e cultural, se diferenciando, no entanto, por serem consideradas acessíveis, em escala mundial ou nacional. Nesse sentido, é mister identificar e analisar as soluções dadas a fim de diminuir os diferentes tipos de barreiras que inviabilizam o acesso das pessoas com deficiência e mobilidade reduzida. Portanto, são apontados aqui os procedimentos metodológicos utilizados em tais exemplos, a fim de perceber em que medida esses se aplicam a São Luís no tocante ao desenvolvimento de projetos possíveis para um Centro Histórico mais acessível.

\section{CIDADES HISTÓRICAS ACESSÍVEIS MUNDO A FORA}

A ideia europeia de acessibilidade, no sentido de "uma sociedade para todos" tem origem na década de 1960 na Suécia com o termo "Design Inclusivo". Já na Universidade Estadual da Carolina do Norte - EUA o termo utilizado é "Design Universal", visando uma vida independente e livre de obstáculos, ou seja, viver com autonomia. A ideia transformou-se em recomendação na Declaração de Estocolmo, na Assembleia Geral Ordinária do Instituto Europeu para o Design Inclusivo (EIDD, 2004). Posteriormente essa ideia se difundiu e vem sendo aplicada em várias cidades no mundo todo. 


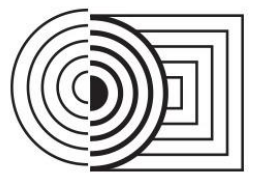

\section{$17^{\circ}$ ERGODESIGN \& USIHC 2019 \\ PUC-Rio, 11 a 13 de dezembro \\ Rio de Janeiro, RJ, Brasil}

$17^{\circ}$ Ergodesign - Congresso Internacional de Ergonomia e Usabilidade

de Interfaces Humano Tecnológica: Produto, Informações Ambientes

Construídos e Transporte

$17^{\circ}$ USIHC - Congresso Internacional de Ergonomia e Usabilidade

de Interfaces Humano Computador

Os EUA definiram sete princípios norteadores do desenho universal: 1. Igualitário - uso equitativo; 2. Adaptável - uso flexível; 3. Óbvio - uso intuitivo; 4. Reconhecível - uso de fácil percepção; 5. Seguro - uso tolerante ao erro; 6. Sem esforço - baixo esforço físico e 7. Abrangente - dimensões razoáveis. Nesse sentido o design pode contribuir na resolução de diferentes problemas com desenvolvimento de projetos, produtos e serviços.

O Plano Nacional de Promoção da Acessibilidade - PNPA, criado em 2007 em Portugal, conta com medidas integradas para a promoção da acessibilidade em espaço edificado, nos transportes, e para Tecnologias de Informação e Comunicação - TIC's e Tecnologias de Apoio TA, criando soluções acessíveis a fim de promover a autonomia, igualdade de oportunidades e participação social de todas as pessoas, como forma de eliminar discriminações (PAIVA, 2009, p. 67-68). Nesse sentido o uso de dispositivos multimídia podem funcionar como uma ferramenta de informação para todos, dentro e fora das edificações culturais, como mesas digitais com imagens, vídeos, textos e áudios, QR Code, contribuindo para a informação das pessoas de modo geral.

Os planos de acessibilidade da Espanha, com base no desenho universal estão consolidados desde as décadas de 1980 e 1990. A Reabilitação do Centro Histórico de Madri colocou em ação o plano geral de ordenação urbana, infra-estrutura e eliminação de barreiras físicas - com pavimentação, rampas, nivelamento entre vias e calçadas, corrimão, sinalização. Lá a preferência é para o pedestre e não para os veículos (RIBEIRO, 2008, p. 65-81; PAIVA, 2009, p. 69-70).

$\mathrm{Na}$ década de 1990 a Holanda tratou questões de mobilidade e acessibilidade inserindo o conceito de espaço compartilhado que comporta o trânsito de veículos públicos, ciclistas, pedestres em espaços que apostam no comportamento entre os diferentes usuários e poder de negociação entre motoristas e pedestres. Nesses casos a velocidade para veículo motor limitase a $30 \mathrm{Km} / \mathrm{h}$. Já para as pessoas com deficiência visual ou situação de vulnerabilidade - crianças e idosos - foi pensado um pavimento de orientação como forma de não se sentirem desamparados. Uma das características desses espaços é a retirada de sinalização esperada em vias para automóveis, da mesma forma que retira placas, semáforos e faixas de pedestres.

$\mathrm{Na}$ Suíça, ruas e áreas residenciais, de preferência pedonal, são sinalizadas com pictogramas indicando a preferência do pedestre e limite máximo de 10 a $20 \mathrm{Km} / \mathrm{h}$ para automóveis. Neste caso não existe barreira física entre calçadas e pista de rolamento, os elementos de desenho urbano, como móveis, ajudam a marcar as prioridades. Já em Madri, existem ruas exclusivamente para uso de pedestres, o pavimento é pensando na escala humana (IPHAN, 2014, p.119-122). Para implantar ações de compartilhamento de ruas é necessário compreender o contexto cultural, além de amplo trabalho de informação junto à população, ou seja, espaços compartilhados remetem aspectos de cidadania, supõe um processo educativo.

Quito no Equador possui plano de mobilidade sustentável com transporte público integrado, vias exclusivas para pedestres e controle de veículos particulares, transferência intermodal de viagens e definição de horário para descarregar mercadorias (IPHAN, 2014, p. 5359). Neste caso estão em evidência as questões da mobilidade dos transportes automotores e menos voltada a acessibilidade na escala humana, pedonal, ciclistas e cadeirantes.

Outras cidades que se destacam pela acessibilidade são Montreal no Canadá - quanto as estações de metrô, museus e catedrais - e a cidade de Berlim, na Alemanha. Essa última desde o ano de 2012 conta com um banco de dados com informações sobre acessibilidade em instalações nos prédios, o que a fez ganhar o prêmio de cidade acessível, da Comissão Europeia. 


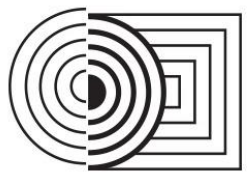

\section{$17^{\circ}$ ERGODESIGN \& USIHC 2019 \\ PUC-Rio, 11 a 13 de dezembro \\ Rio de Janeiro, RJ, Brasil}

$17^{\circ}$ Ergodesign - Congresso Internacional de Ergonomia e Usabilidade de Interfaces Humano Tecnológica: Produto, Informações Ambientes Construídos e Transporte

$17^{\circ}$ USIHC - Congresso Internacional de Ergonomia e Usabilidade

de Interfaces Humano Computador

A Alemanha figurou como um dos países mais acessíveis para turistas em 2016, contando com prédios adaptados como museus e hotéis, além de rotas acessíveis. Bora, na Suécia, também já ganhou o título de cidade mais acessível da Europa (SANTOS, 2018, p. 81-84).

Salamanca, na Espanha, é considerada cidade de todos e para todos por trabalhar na perspectiva de eliminação de todo tipo de barreira. Também naquele país, na cidade de Ávila existe uma rota acessível que atravessa os principais pontos turísticos.

De acordo com os exemplos acima percebe-se que o entendimento sobre cidades históricas acessíveis, bem como as soluções encontradas e aplicadas, variam de lugar para lugar e podem ser muito diferentes.

\section{CENTROS HISTÓRICOS ACESSÍVEIS E AS EXPERIÊNCIAS NO BRASIL}

No Brasil as iniciativas para que tenhamos centros históricos acessíveis ainda são recentes e pontuais. Na tentativa de estabelecer diretrizes gerais sobre mobilidade e acessibilidade em centros históricos, o IPHAN (2014) lançou um caderno técnico com exemplos de ações reconhecidas e validadas pelo mesmo. Citou Curitiba como pioneira, com destaque para o sistema de transporte. Em 1994 o projeto "Rio Cidade" criou uma rota acessível, considerando a NBR 9050 e preceitos do design universal, entretanto não foi dada continuidade as intervenções e manutenções. Em 2016 as Paraolimpíadas motivaram o trabalho em prol da acessibilidade no Rio de Janeiro, mas passado o evento parte da estrutura ficou sem manutenção. Essa situação chama a atenção para o descaso com os bens públicos, autonomia da pessoa com deficiência e qualidade de vida da população.

No ano 2000 aconteceu o projeto "Pirenópolis sem barreiras", "patrimônio para todos" com discussão de problemas e soluções, que envolveu representantes da sociedade civil, Ministério Público e gestores das esferas estadual e federal - esse aspecto do processo metodológico, marcado pela participação popular, é destacado pelo IPHAN (2014). Foram construídas quatro rotas acessíveis na cidade de Goiás, considerando roteiro histórico e serviços. Entretanto Ribeiro (2008), alerta para projeto ruins ou de má execução, destacando algumas rampas fora do padrão, a falta de corrimãos e guarda-corpos. A crítica feita por essa autora, chama atenção para o questionamento sobre o tipo e nível de participação de pessoas com deficiência e mobilidade reduzida nesse processo. De acordo com o lema "nada sobre nós sem nós", adotado por pessoas com deficiência, não há alguém mais indicado para falar sobre as necessidades e anseios da pessoa com deficiência do que ela própria.

Frente às iniciativas e processos em curso, é possível associar a perspectiva do design universal, considerando a NBR 9050 com o design participativo, sendo estas ferramentas fundamentais no encontro de soluções para as cidades inclusivas. O design deve adotar variados métodos e técnicas. Para fazer coleta de dados são muito uteis o grupo focal, observação, entrevistas, questionários.

lida (2005) auxilia nessa reflexão ao lembrar que a ergonomia começa com o estudo das características do trabalhador para posteriormente projetar o que ele consegue executar. $\mathrm{O}$ trabalho então, deve ser analisado na sua totalidade, considerando os aspectos físicos, cognitivos, sociais, organizacionais, ambientais e outros. Assim, as necessidades do homem estão refletidas nas metodologias dos autores. 


\section{$17^{\circ}$ ERGODESIGN \& USIHC 2019}

PUC-Rio, 11 a 13 de dezembro

Rio de Janeiro, RJ, Brasil $17^{\circ}$ Ergodesign - Congresso Internacional de Ergonomia e Usabilidade de Interfaces Humano Tecnológica: Produto, Informações Ambientes Construídos e Transporte

$17^{\circ}$ USIHC - Congresso Internacional de Ergonomia e Usabilidade de Interfaces Humano Computador

Nesse sentido Lobach (2001) ressalta que as ideias são materializadas afim de suprirem necessidades. E que, portanto, todo projeto deve ser questionado quanto a sua importância para a sociedade, bem como se o resultado do processo de planejamento é sensato e quais os seus efeitos positivos e negativos.

Corroborando com os autores acima, Bonsiepe (2011) lembra que o humanismo projetual está na habilidade de entender as necessidades da sociedade e converte-las em soluções para promoção da segurança e da autonomia do cidadão, de modo geral; destaca ainda a importância de uma consciência crítica para a prática projetual, cita o design participativo enquanto prática especialmente na arquitetura e urbanismo, desde 1970. Assim, percebe-se o designer como colaborador no desenvolvimento de projetos e soluções para o dia a dia das pessoas. Realçando a importância da participação dos usuários em cada etapa do desenvolvimento de produtos ou serviços.

Bonsipe pensa o "desenvolvimento pelo design" dando o mesmo peso à alta tecnologia e mudança social. Ele defende o uso de tecnologias apropriadas para cada local considerando o design de produtos sustentáveis. Enquanto Papanek defende o design para a necessidade, Bonsipe defende o "design com" e "design em" trabalhando no local e em relação de intercâmbio com os conhecimentos do lugar (PATROCÍNIO, 2015). Já Bolton e Park citam três níveis para o envolvimento dos usuários no processo de criação de produtos: (a) indireto (design para); (b) participativo (design com); e (c) cocriação (design por)" (apud PATROCíNIO 2015, p.68).

Figura 01 - Escada Virtuosa do Design e do Desenvolvimento FOTO: Patrocínio, 2015

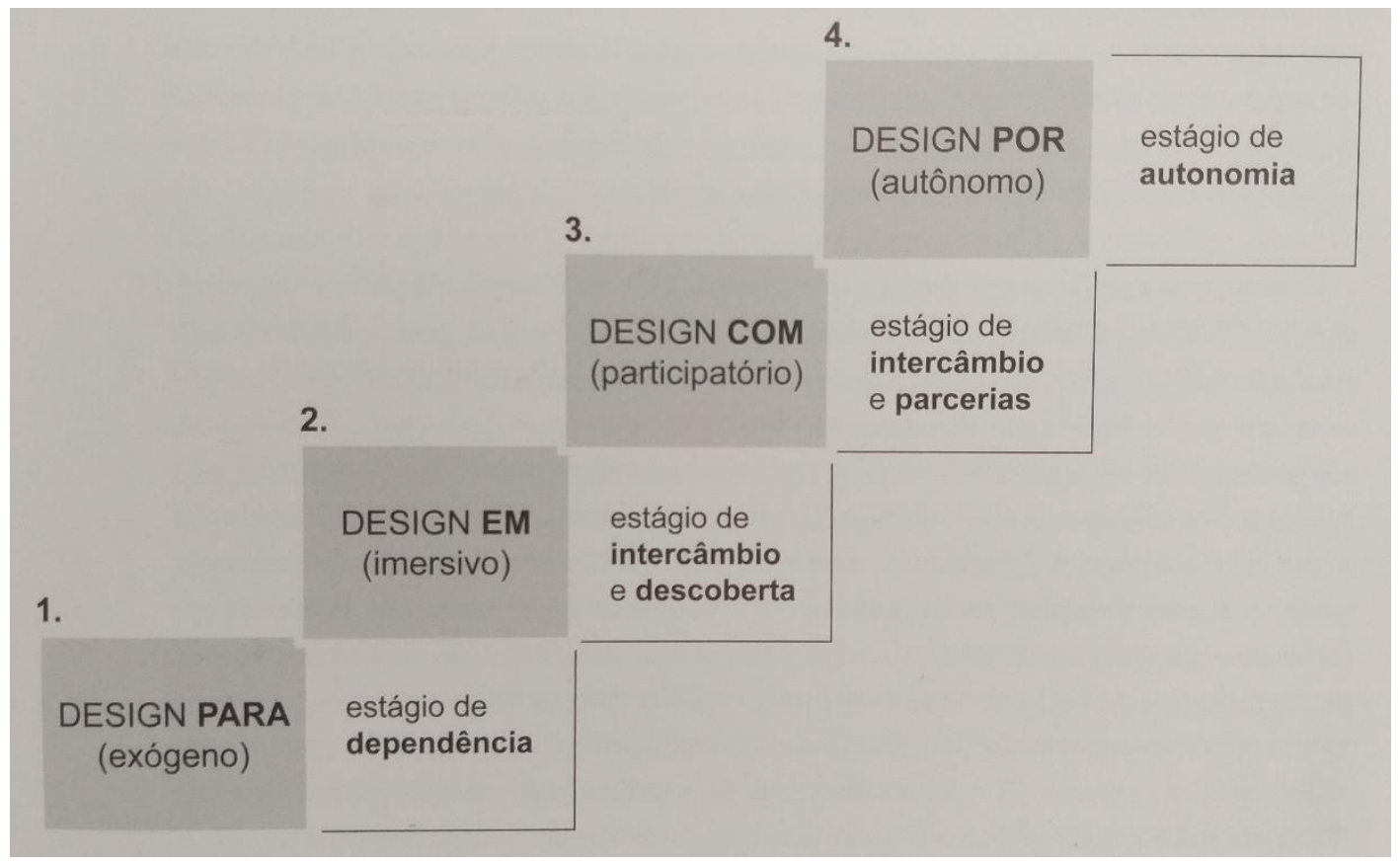

Tomando por base esses exemplos, Patrocínio (2015) elabora um modelo de evolução progressiva em quatro degraus que sai de um estágio de dependência para a autonomia do 


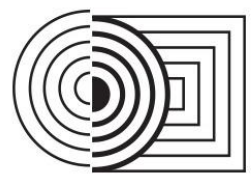

\section{$17^{\circ}$ ERGODESIGN \& USIHC 2019 \\ PUC-Rio, 11 a 13 de dezembro \\ Rio de Janeiro, RJ, Brasil}

$17^{\circ}$ Ergodesign - Congresso Internacional de Ergonomia e Usabilidade de Interfaces Humano Tecnológica: Produto, Informações Ambientes Construídos e Transporte

$17^{\circ}$ USIHC - Congresso Internacional de Ergonomia e Usabilidade de Interfaces Humano Computador

design, a Escada Virtuosa do Design e do Desenvolvimento, (ver figura 01). São eles: Design para (exógeno) - estágio intervencionista, assistencialista, quando o designer baseado em pesquisas desenvolve projetos para o local; Design em (imersivo) - ainda intervencionista, mas fica imerso procurando compreender a cultura e conhecimento local, em relação de intercâmbio; Design com (participatório) - com parcerias estabelecidas o designer traz novos conhecimentos, tecnologias ou métodos para compartilhar no fazer do projeto com seus pares locais; Design por (autônomo) - pode haver parcerias e intercâmbios, mas estes se darão entre iguais, todos tem uma bagagem e com ela contribuem para o desenvolvimento de um design local e por locais. Os conceitos de necessidades básicas e de design como fator de desenvolvimento se encontram em uma versão contemporânea de design para o interesse social (Patrocínio, 2015). O Design com, ou seja, design participativo, acontece na contemporaneidade em um nível de parceria com o usuário.

No Centro Histórico de Salvador, um ícone é o elevador Lacerda que liga a cidade alta à cidade baixa. A cidade conta com uma rota acessível no bairro do Pelourinho, desde de 2013, onde foram implantados elementos como rampas com corrimão, rebaixamento de guias e nivelamento de vias.

Nota-se que quando o tema é mobilidade e acessibilidade urbana, o Brasil está apenas no início do processo e cabe ainda investigar se as necessárias avaliações foram feitas sobre essas primeiras experiências, por quem e quais os resultados obtidos.

Quanto aos projetos brasileiros o IPHAN aprovou a realização de quatro, são eles: o plano de Laguna e de São Francisco, ambos em Santa Catarina; de Paranaguá, no Paraná e de Ouro Preto, em Minas Gerais.

Os principais problemas apontados no caso de Laguna foram tráfego intenso de veículos, falta de segurança para pedestres e ciclistas, e falta de sinalização. Como solução as propostas foram a implantação de sinalização de orientação; zona de velocidades diferenciadas para pedestres, ciclistas, cadeirantes e automóveis; manutenção do passeio, em uniformidade com o desenho universal, conceito de espaço compartilhado e elevação da via ao nível do passeio. (IPHAN, 2014, p. 69-72).

Em São Francisco os problemas apontados foram estacionamento dentro do centro, veículos pesados, poluição sonora e visual. Assim, as propostas foram calçadas mais largas, construção de ciclovias, área de estacionamento mais afastada, melhor sistema de transporte público, alternativa de transporte como VLT, bonde, veículo elétrico (IPHAN, 2014, p.77).

Paranaguá pensou soluções para melhor circulação de pessoas a pé, adotando tipologias para as ruas, melhor calçamentos, sinalização para os diferentes modais - pedestres, ciclistas e motoristas -, incentivo ao uso de coletivos e horário para carga e descarga de mercadorias. Segundo o IPHAN (2014), o diferencial foi a participação popular no "dia da mobilização", quando as pessoas apontaram problemas e soluções para a cidade, realização de manifestações culturais e criação de blog para o acompanhamento do trabalho (p.78-79).

O diagnóstico de Ouro Preto passou por calçadas estreitas, falta de sinalização correta e estacionamento de todo tipo de veículo na Praça Tiradentes. As propostas foram sistema de transporte de baixo impacto ambiental, qualificação de espaços e vias, priorização de deslocamento a pé e plano para estacionamento, implantação de infraestrutura para transporte de pessoas, como elevadores e escadas rolantes, implantação de ciclovias, construção de pontos intermodais, sinalização e fiscalização de trânsito, (IPHAN, 2014, p.73). Entre as intervenções em edifícios históricos, o Museu da Inconfidência instalou mecanismo de transporte inclinado 
para cadeiras de rodas (COSTA, 2016, p 70-71) - ver figura 02. Entretanto, outras alternativas podem ser adotadas, como plataformas elevatórias para transposição de escadas - ver figura 03 -, a exemplo de países como EUA e cidades da Europa. Com as novas tecnologias diferentes recursos surgem e podem ser adaptados para contribuir com as seis dimensões da acessibilidade que são: a arquitetônica, comunicacional, metodológica, instrumental, programática e atitudinal.

Figura 02 - Mecanismo de transporte Inclinado para cadeira de rodas FOTO: IPHAN, 2014

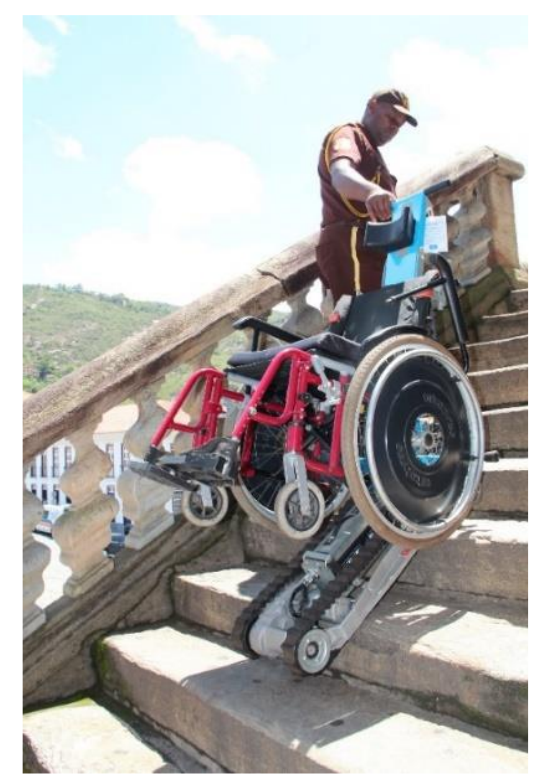

Figura 03 - Plataforma elevatória FOTO:www.stannah,pt/mobilidade/plataformas-elevatórias-paraescadas, 2019

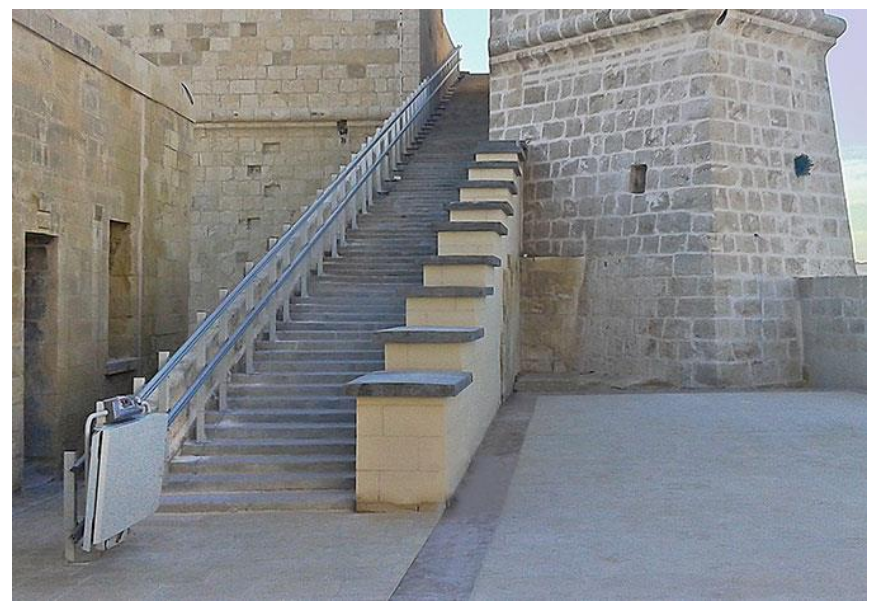

\section{ACESSIBILIDADE NO CENTRO HISTÓRICO DE SÃO LUÍS}

Quanto a questão da mobilidade e acessibilidade no Centro Histórico de São Luís alguns aspectos podem ser destacados no recorte espacial da pesquisa. Há um terminal de integração de ônibus, mas apenas parte da frota conta com plataforma elevatória e nem sempre estas funcionam. No quesito estacionamento existe uma grande área reservada e com vagas para idosos, grávidas e pessoas com deficiência - com sinalização horizontal - entretanto hoje se mostra insuficiente e ineficiente quanto a sinalização vertical. No Bairro da praia Grande as ruas internas não permitem a circulação de veículos automotores. No centro histórico observa-se algumas rampas de acesso entre vias e calçadas inadequadas, danificadas ou obstruídas algumas vezes com vendedores ambulantes. As ruas de paralelepípedo são muito irregulares, dificultando o acesso não só de pessoas com deficiência e mobilidade reduzida. As condições das calçadas e a diferença de nível com relação aos imóveis são obstáculos. Alguns pontos de sinalização, orientação e lixeiras são inadequados, obstruindo calçadas. A sinalização é precária quanto a informação e orientação. A falta de piso podotátil e pisos de alerta dificultam a orientação de pessoas com deficiência visual. A elevada diferença de nível entre o bairro da Praia Grande e a Praça Pedro II é vencida por grande escadaria ou ladeira bastante íngreme em via 


\section{$17^{\circ}$ ERGODESIGN \& USIHC 2019}

PUC-Rio, 11 a 13 de dezembro

Rio de Janeiro, RJ, Brasil $17^{\circ}$ Ergodesign - Congresso Internacional de Ergonomia e Usabilidade de Interfaces Humano Tecnológica: Produto, Informações Ambientes Construídos e Transporte

$17^{\circ}$ USIHC - Congresso Internacional de Ergonomia e Usabilidade

de Interfaces Humano Computador

compartilhada com veículos automotores e calçadas acidentadas, constituindo grande barreira para o pessoas com deficiência.

Uma inciativa recente, de 2019, no campo da acessibilidade no bairro da Praia Grande são os três carrinhos elétricos (ver figuras 04 e 05) - que ficam estacionados na frente do Centro de Criatividade Domingos Costa Filho - para transportar pessoas com deficiência ou mobilidade reduzida. A despeito de trazer inovação e atualidade no que tange a ampliação de possibilidades de acesso ao sítio urbano, há um duplo limite. Em primeiro lugar esses veículos são destinados ao deslocamento até à Defensoria Pública Estadual - DPE, alcançando apenas duas ruas, em segundo lugar seu uso é restrito aos usuários daquela instituição. Portanto, além de ser um percurso muito curto não atende as pessoas que precisam se deslocar para outros pontos do bairro. Nesse sentido, faz-se necessário um serviço de carros elétricos que cubra uma área maior do centro antigo, bem como atenda todas as pessoas com deficiência e mobilidade reduzida para além dos interesses da DPE.

Figura 04 e 05 - Carros elétricos para transportes de pessoas com deficiência ou mobilidade reduzida. FOTO: Acervo autora, 2019
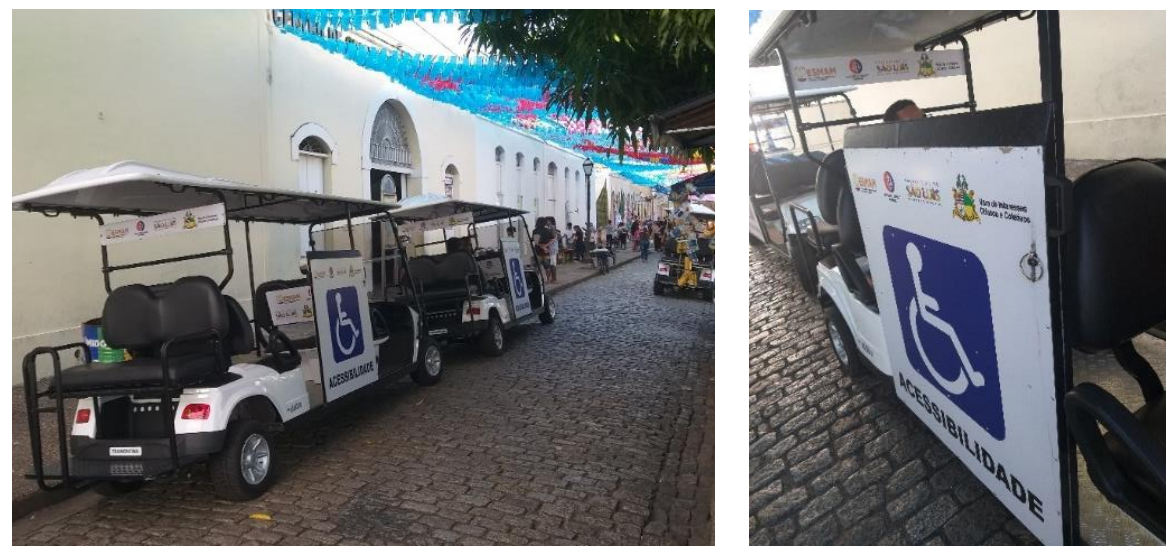

Já está em curso um Projeto de Mobilidade e Acessibilidade para o Centro Histórico de São Luís, que coincide com a área do patrimônio mundial. A Secretaria de Planejamento Urbano do Município - SEPLAM é responsável pelo plano de Acessibilidade e está finalizando a primeira etapa de três do projeto. Esta primeira etapa - no bairro da Praia Grande - assim como as outras, deve ser submetida a 3 ${ }^{a}$ SR/IPHAN para aprovação e posterior execução. Não se tem notícia de que as pessoas com deficiências tenha sido informadas sobre o projeto de acessibilidade para 0 Centro Histórico de São Luís. Nem sabe-se da previsão de algum nível de participação do público em questão bem como dos usuários de modo geral em alguma etapas do projeto. 


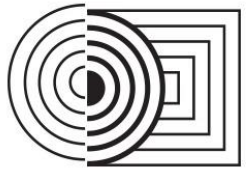

\section{$17^{\circ}$ ERGODESIGN \& USIHC 2019 \\ PUC-Rio, 11 a 13 de dezembro \\ Rio de Janeiro, RJ, Brasil}

$17^{\circ}$ Ergodesign - Congresso Internacional de Ergonomia e Usabilidade de Interfaces Humano Tecnológica: Produto, Informações Ambientes Construídos e Transporte

$17^{\circ}$ USIHC - Congresso Internacional de Ergonomia e Usabilidade de Interfaces Humano Computador

\section{CONSIDERAÇÕES FINAIS}

Entende-se que não é fácil tornar uma cidade histórica acessível. Entretanto, em pleno século XXI, com todas as experiências de acessibilidade e mobilidade já implementadas mundo a fora, e considerando as novas tecnologias, o Brasil já deveria dispor de ações mais eficazes em todas ou muitas cidades históricas. Embora não seja possível considerar que o país tenha cidades integralmente acessíveis, o que ainda é realidade distante, algumas ações pontuais quanto a mobilidade e acessibilidade foram feitas. Há que se discutir seus pontos positivos e negativos.

Em São Luís alguns problema detectados no primeiro momento. Há um terminal de integração de ônibus no recorte espacial da pesquisa, mas apenas parte da frota conta com plataforma elevatória e nem sempre estas funcionam. O estacionamento de carros particulares hoje se mostra insuficiente e ineficiente quanto a sinalização vertical. Algumas rampas de acesso entre vias e calçadas estão inadequadas, danificadas ou obstruídas. O pavimento de paralelepípedo é muito irregular, dificultando o acesso das pessoas. As condições das calçadas e a diferença de nível com relação aos imóveis são obstáculos. Bem como pontos de sinalização, orientação e lixeiras obstruindo calçadas. A sinalização é precária quanto a informação e orientação. A falta de piso podotátil e pisos de alerta dificultam a orientação de pessoas com deficiência visual. A elevada diferença de nível entre o bairro da Praia Grande e a Praça Pedro II é vencida por grande escadaria ou ladeira bastante íngreme em via compartilhada com veículos automotores e calçadas acidentadas, constituindo grande barreira para o pessoas com deficiência.

Atualmente três carrinhos elétricos transportam pessoas com deficiência ou mobilidade reduzida, mas existe um duplo limite, pois os veículos são destinados ao deslocamento só até à Defensoria Pública Estadual - DPE e uso é restrito aos usuários daquela instituição. Portanto, além de ser um percurso muito curto não atende as pessoas que precisam se deslocar para outros pontos do bairro. Nesse sentido, faz-se necessário um serviço de carros elétricos que cubra uma área maior do centro antigo, bem como atenda todas as pessoas com deficiência e mobilidade reduzida para além dos interesses da DPE.

Vale lembrar que já está em curso um Projeto de Mobilidade e Acessibilidade para o Centro Histórico de São Luís, entretanto não se tem notícias de que pessoas com deficiência, ou organizações e movimentos representativos desse segmento tenham sido consultadas sobre suas necessidades e expectativas.

Experiências utilizadas em cidades históricas no Brasil e no mundo podem e devem ser discutidas - entre gestores, universidades, pessoas com deficiências e usuários de modo geral afim de ajudar na elaboração de soluções para tornar o centro histórico de São Luís acessível. De outro lado, importa ter claro que as experiências e projetos não podem ser apenas replicados mas adaptados às particularidades de cada lugar. As análises e avaliações sobre os processos em curso, ou já consolidados como boas práticas, servem como inspiração. Considerando o conceito de desenho universal, a NBR 9050/2015 em conjunto com métodos de design participativo e técnicas como grupo focal, entrevistas, visita "in loco" devem colaborar no encontro de soluções para o caso de São Luís. Tais ações precisam ser testadas e validadas pelos usuários, estes devem ser ouvidos e as correções devem ser efetivadas até que se possa usufruir de cidades acessíveis por todo o Brasil. Assim, a ideia de uma cidade desenhada para todos se completa quando contribui com a quebra de barreiras físicas e atitudinais. 


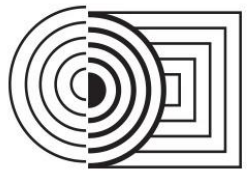

\section{$17^{\circ}$ ERGODESIGN \& USIHC 2019 \\ PUC-Rio, 11 a 13 de dezembro \\ Rio de Janeiro, RJ, Brasil}

$17^{\circ}$ Ergodesign - Congresso Internacional de Ergonomia e Usabilidade de Interfaces Humano Tecnológica: Produto, Informações Ambientes Construídos e Transporte

$17^{\circ}$ USIHC - Congresso Internacional de Ergonomia e Usabilidade

de Interfaces Humano Computador

\section{REFERÊNCIAS BIBLIOGRÁFICAS}

ASSOCIAÇÃO BRASILEIRA DE NORMAS TÉCNICAS - ABNT. NBR 9050. Acessibilidade a edificações, mobiliário, espaços e equipamentos urbanos. 2 ed. Rio de Janeiro, 2015.

ANDRÉS, Luiz Phelipe de Carvalho Castro. Centro Histórico de São Luís Maranhão: patrimônio mundial. São Paulo: Audichromo, 1998, p.48.

BRASIL. Constituição da República Federativa do Brasil, promulgada em 5 de outubro de 1988. Obra coletiva de autoria da Editora Saraiva com a colaboração de Antônio Luiz de Toledo Pinto, Márcia Cristina Vaz dos Santos Windt e Lívia Céspedes. 38ª edição. São Paulo: Saraiva, 2006.

BONSIEPE, Gui. Design, Cultura e Sociedade. São Paulo: Edgar Blucher Ltda, 2011.

COSTA, Raíssa de Keller e. Acessibilidade e Preservação no Patrimônio Cultural da Cidade de Ouro Preto, Minas Gerais. Dissertação de Mestrado. Programa de pós-graduação em Ambiente Construído e Patrimônio Sustentável da Escola de Arquitetura da Universidade Federal de Minas Gerais, 2016.

EIDD. Declaração de Estocolmo. Assembleia Geral Ordinária do Instituto Europeu para o Design Inclusivo. Assinada em 9 de maio de 2004. Disponível em: http://dfaeurope.eu/wpcontent/uploads/2014/05/Stockholm-Declaration portuguese.pdf. Acesso em 15/06/2015.

https://www.stannah.pt/mobilidade/plataformas-elevatorias-para-escadas.Acesso em 01/08/2019.

IIDA, Itiro. Ergonomia: projeto e produção. São Paulo: Edgar Blucher, p. 139-263, 1992.

INSTITUTO BRASILEIRO DE GEOGRAFIA E ESTATÍSTICA. CENSO Demográfico. Perfil dos Idosos Responsáveis pelos Domicílios. Rio de Janeiro. Disponível em: http://www.ibge.gov.br/home/presidencia/notícias/25072002pidodo.shtm. $\quad$ Acesso $\quad \mathrm{em}$ 13.09.2015.

IPHAN. Cartas Patrimoniais. Rio de Janeiro: IPHAN, 2004.

. Mobilidade e acessibilidade urbana em centros históricos. (Organização de Sandra Bernardes Ribeiro), 120p, (Cadernos Técnicos:9), Brasília: IPHAN, 2014.

MAGALHÃES, Aloísio. E triunfo? A questão dos bens culturais no Brasil. Rio de Janeiro: Nova Fronteira, Fundação Nacional Pró-Memória, 1985.

MEIRELES, Mário M. História do Maranhão. 4aㅡ ed. Rev. Imperatriz, MA: Ética, 2008.

MORAES, Anamaria de, MONT'ALVÃO, Cláudia. Ergonomia: conceitos e aplicações. Rio de Janeiro:2AB, 2009 (4ª edição, ampliada), p. 79-143.

PAIVA, Ellayne Kelly Gama de. Acessibilidade e preservação em sítios históricos: o caso de São Luís do Maranhão. Dissertação de mestrado. Programa de Pesquisa e Pós-Graduação PPG/FAU, Faculdade de Arquitetura e Urbanismo, Universidade de Brasília, 2009.

PATROCÍNIO, Gabriel e NUNES, J.M. Design e desenvolvimento 40 anos depois. São Paulo, Blucher, 2015.

RIBEIRO, Gabriela Sousa. Proposta de procedimentos metodológicos para avaliação da acessibilidade física em sítios históricos urbanos. Dissertação de mestrado. Programa de pós-graduação em Design. UFPE, 2008. 
SANTOS, Katia Virginia Espínola Rodrigues do. Desafios para a acessibilidade física: um estudo no Centro Histórico de São Luís para pessoa usuária de cadeira de rodas. Dissertação de mestrado profissional em Turismo. Universidade de Brasília, 2009.

\section{AGRADECIMENTOS}

O presente trabalho é parte das atividades do Projeto DINTER UFMA/UNESP e foi realizado com apoio da Coordenação de Aperfeiçoamento de Pessoal de nível Superior - Brasil (CAPES); da Fundação de Amparo à Pesquisa e ao Desenvolvimento Científico e Tecnológico do Maranhão (FAPEMA edital 012/201, processo 04206/2016) e do CNPq (Processo 304619/2018-3). 